\title{
Rainfall - Runoff Modeling: A Comparative Analyses: Semi Distributed HBV Light and SWAT Models in Geba Catchment, Upper Tekeze Basin, Ethiopia
}

\author{
Abebe Temesgen \\ Faculty of Hydraulic and Water Resources Engineering \\ Arbaminch Water Technology Institute ,Arbaminch University \\ P.O.Box 21, Arbaminch, Ethiopia
}

\begin{abstract}
This study was conducted to identify the best hydrological models in simulating the discharge in a comparative approach /SWAT and HBV light/ at Geba cathment and identifying of models which represent realistic simulation at sub basin scale. The various modelling procedure (i.e input data, sensitivity analsis, calibration, validation and uncertainty assessment) were employed to test the models performance. The results shows that K2, MAXBAS , BETA are more sensitive than other model parameters in HBV light model and CN2, GWQMN and SOL_AWC are more sensitive parameters in case of SWAT. The calibration results of HBV light and SWAT as evaluated by $\mathrm{E}_{\mathrm{NS}}, \mathrm{R}^{2}$ and PBIAS are $0.70,0.71$ and $0.73,0.81,-11 \%$ respectively. Moreover, an $\mathrm{E}_{\mathrm{NS}}, \mathrm{R}^{2}$ and PBIAS of 0.71 , 0.72 and $0.72,0.72,4.1 \%$ were obtained during validation Period for HBV light and SWAT models respectively. From the uncertainity plot for HBV light most of the simulated flow are inside the 95PPU with high predictive uncertainity band in Monte Carlo Simulation as comparsion with the SWAT CUP uncertainity analysis by SUFI 2 and from the uncertainity plot in SWAT model most of the simulated hydrograph is outside the upper and lower band and less predictive uncertainiy. These mentioned results depicted that both models are well reasonably simulated the discharge of Geba catchment and from uncertainity and identifiability of parameter applying HBV light model could be effective in simulation of runoff for sustainable water resources management in the watershed runoff
\end{abstract}

Keywords: Flow simulation, Comparative analysis, HBV light, SWAT, Uncertainty, Geba cathment DOI: $10.7176 / C E R / 11-9-03$

Publication date:October $31^{\text {st }} 2019$

\section{INTRODUCTION}

Developing the basic relationships between the different hydrologic systems like rainfall, runoff, soil moisture, ground water level and land use land cover are crucial for effective and sustainable water resources planning and management activities with the support of hydrological models (Birhane et al.2013).

Models are generally used as utility or supporting tools in various areas of water resources development, in assessing the available water resources in different areas for studying the impacts of human interference in an area such as land use change, deforestation and other hydraulics structures such as dams and reservoirs (Moreda, 1999)

Lack of data is one of the main limitations for hydrological modeling. However, it is often used as a justification for over simplifying, poorly performing models (IHMS,2006). If we want to enhance our understanding of hydrological systems, it is important to fully exploit the information contained in the available data, and to learn from model deficiencies (Fenicia et al.,2008).

In order to model rainfall-runoff process, a variety of hydrological models have been applied (Hundecha, 2005). But the applications of models are different due to the fact that catchments are heterogeneous; In this regard comparative studies in modeling would enable to identify suitable model for understanding hydrological processes better and prediction of environmental changes. Moreover, in data scarce region e.g. Tekeze basin and understanding of catchment behavior and impact assessment are crucial from the perspective of sustainable water resources development point of view. Thus, this research will be conducted in the Geba cathment of upper Tekeze sub basin with the aim of identifying better model in predicting discharge in terms of model conceptualization, parameterization and capturing the response mode of the daily hydrographs during the wet and dry seasons.

\section{MATERIALS AND METHODS}

\subsection{Description of Study Area}

The Geba watershed drains the north-eastern part of the Tekeze River Basin and is located in northern Ethiopia, Tigray Regional State. This research focuses on the upper part of the watershed which covers about $2437.52 \mathrm{~km}^{2}$. The study area is bounded between latitudes $13^{\circ} 16^{\prime}$ and $14^{\circ} 16^{\prime}$ North and longitudes $38^{\circ} 38^{\prime}$ and $39^{\circ} 49^{\prime}$ East. There is a considerable variation in altitudes over the basin with a maximum altitude of $3298.45 \mathrm{~m}$ a.s.1., a minimum altitude of $1747.04 \mathrm{~m}$ a.s.l and an average altitude of $2000 \mathrm{~m}$ a.s.l. (Gonfa, 1996) The topography of the basin is highly controlled by erosion features and geological structures. Sharp cliffs and steep slopes occurs along the major 
rivers.(Abraha,2009)

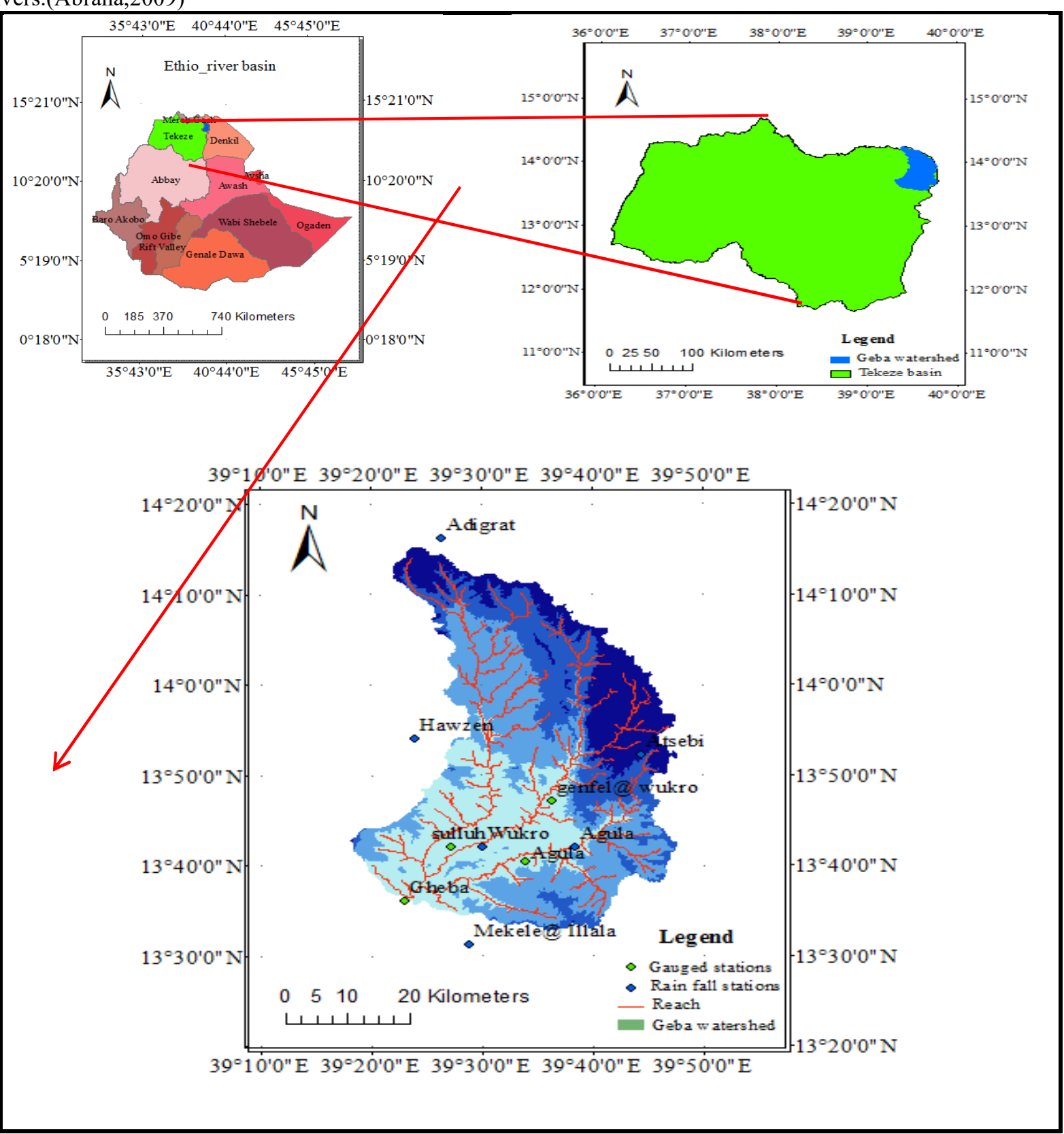

Figure 2.1 Location of the study area

\section{Data Collection}

The metrological and hydrological data required for this study were collected from Ethiopian national meterologiocal agency (NMA) and ministry of water irrigation and electricity (MoWIE). Metrological data from 1992-2012 , flow data from 2002-2012 were collected and DEM (Digital elevation model of 30*30 was collected from Ethiopian mapping agency .Soil map and LULC is obtained from MoWIE

\section{Data Analysis}

In this study station average and normal ratio method were used to complete missing data of all stations. Double mass curve was used to check the homogeneity and consistency of rainfall as well for adjustment of inconsistent data. The Penman-Monteith method is recommended as the sole method for determining reference evapotranspiration (ETo) when the standard meteorological variables including air temperature, relative humidity and sunshine hours data are available (Kumela, 2011). However, those data are not available in all stations in this study area. So, Potential evapotranspiration was calculated by using Hargreaves method since most of the stations have maximum and minimum temperature in all stations.

\section{Model Sensitivity Analysis}

Sensitivity analysis was applied manually by changing the value of one model parameter at a time for SWAT model through SWAT CUP and Monte Carlo Simulation for HBV light model. That is the value of each model 
parameter was increased and decreased up to $60 \%$ by $20 \%$ interval and those having steep slopes are considered as most sensitive while those having moderate to gentle slopes are less sensitive.

\section{Model Calibration}

It was performed manually by trial and error from 2002 to 2012 by changing one model parameter at a time until the model simulated stream flow match with observed stream flow.

\section{Model Performance}

For this study the model performance was evaluated by $\mathrm{E}_{\mathrm{NS}}, \mathrm{R}^{2}$ and PBIAS for HBV light and SWAT models respectively for the calibration and validation period.

Uncertainity analysis for both Models

Due to errors in different condition either in input data, model performance or parameter selection the model commonly affected by uncertainity. For this study Monte carlo simulation procedure (Iuliia et.al, 2014) and SWAT CUP through SUFI 2 (Abbaspour et al. 2009) was used for HBV light and SWAT model respectively.

\section{Results And Disscussions}

\subsection{Model Development HBV Light}

\subsubsection{Sensitivity Analysis}

For Geba cathment the most sensitive parameters are $\mathrm{K} 2$, MAXBAS and BETA where as the rest model parameters are less sensitive or insensitive through out the simulation period.

And from the below the dominant process for the HBV light model is subsurface or ground water dominance since as compared to others its $\mathrm{k} 2$ ( storage or recession coefficient at box 2) is sensitive through out the objective functions.

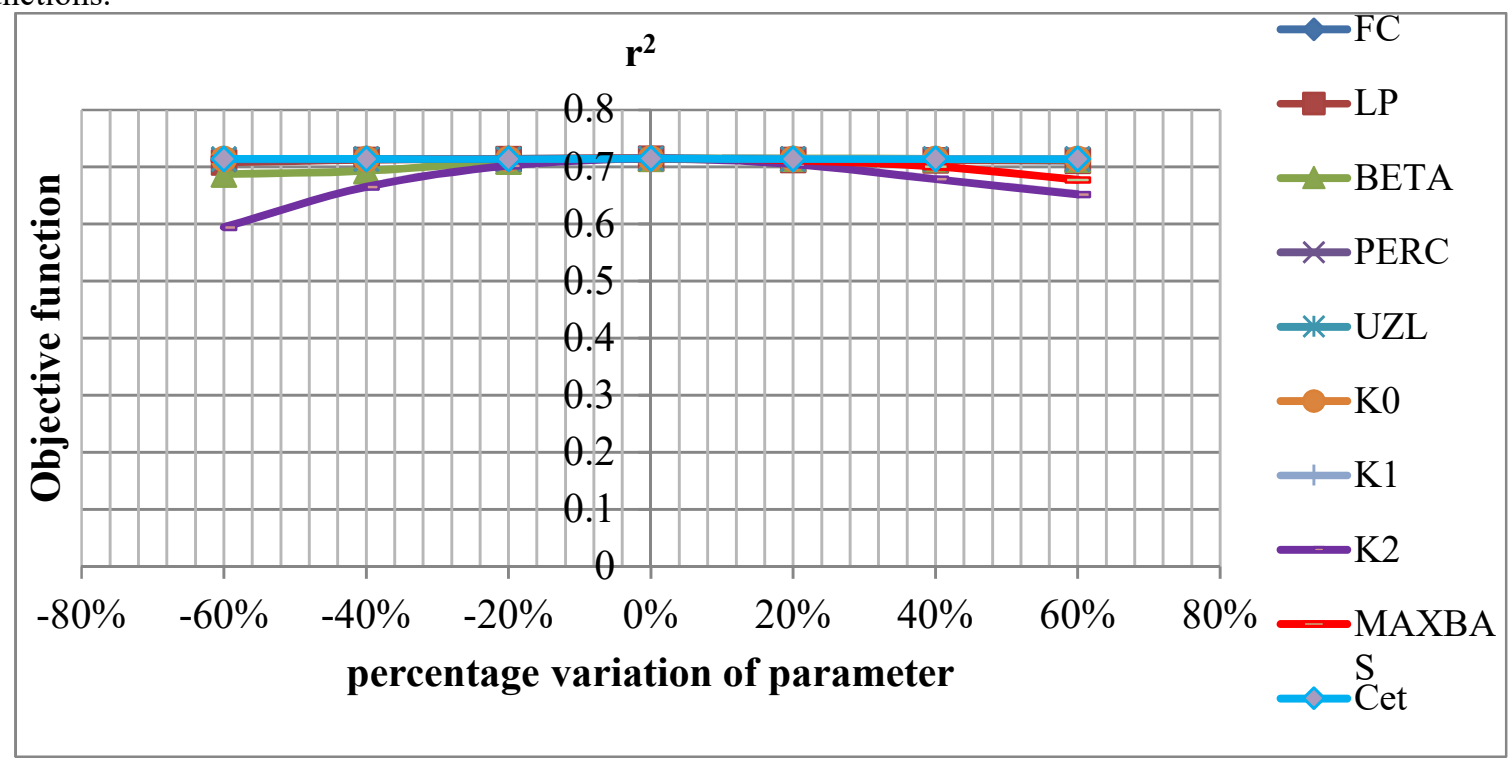

Figure 3.1: Sensitivity analysis by considering $\mathrm{r}^{2}$

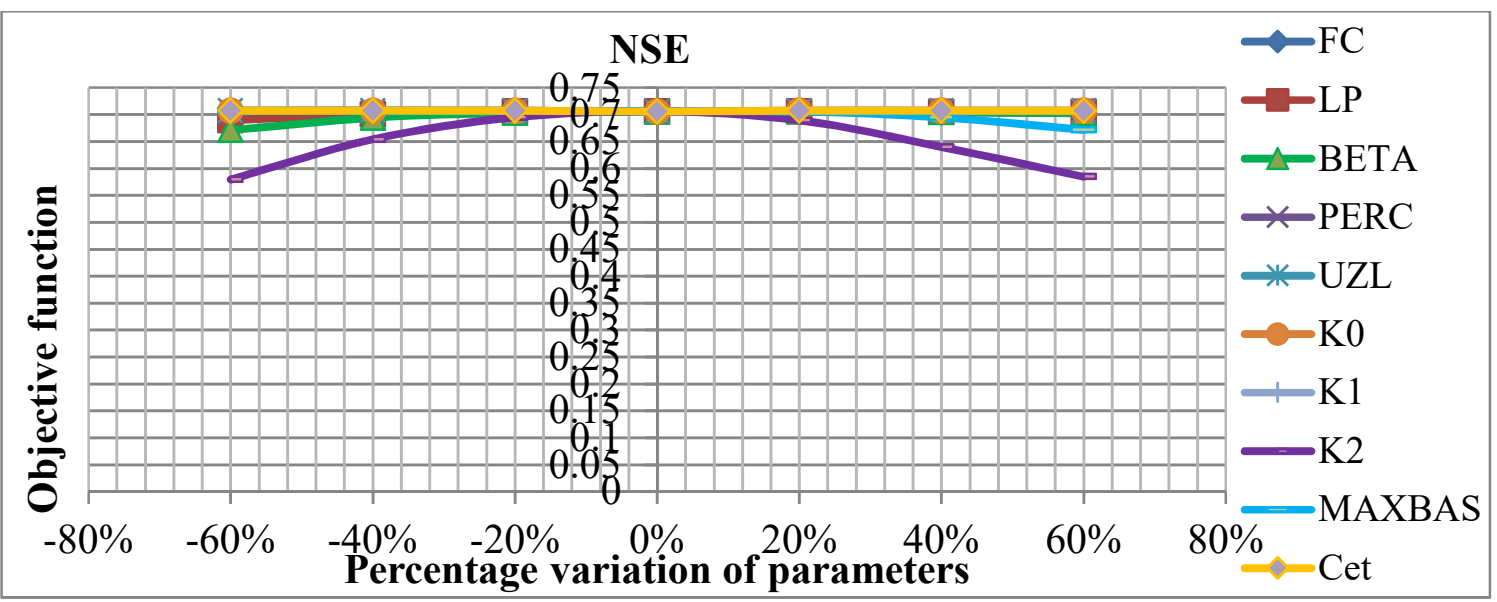

Figure 3.2: Sensitivity analysis by considering NSE 


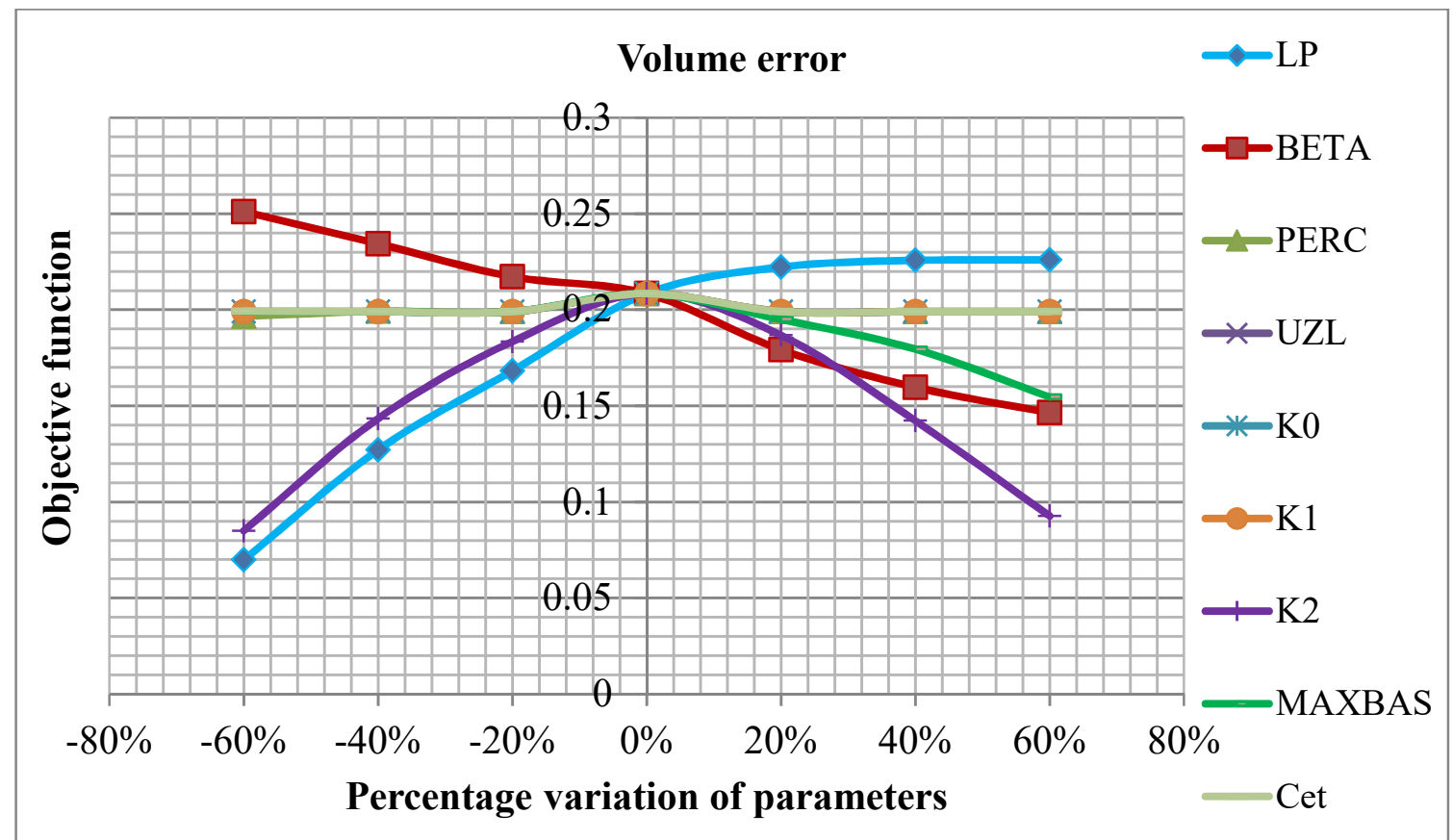

\subsubsection{Calibration and validation}

Figure 3.3: Sensitivity analysis by considering volume error

Eight years (from January 1, 2002 to December 31, 2009) which includes one years of warm up, (from January 1, 2002 to December 31, 2003). And for the validation from January 2010-Dec 2012 the model performance of Geba watershed by HBV light model are satisfactory with objective functions like NSE and $\mathrm{R}^{2}$ greater than 0.60 and $\operatorname{Reff}=0.7145, \mathrm{NSE}=0.707$ and $\operatorname{Reff}=0.71, \mathrm{NSE}=0.71$ for the calibration and validation period



Figure 3.4: Observed and simulated flow hydrographs during calibration period 


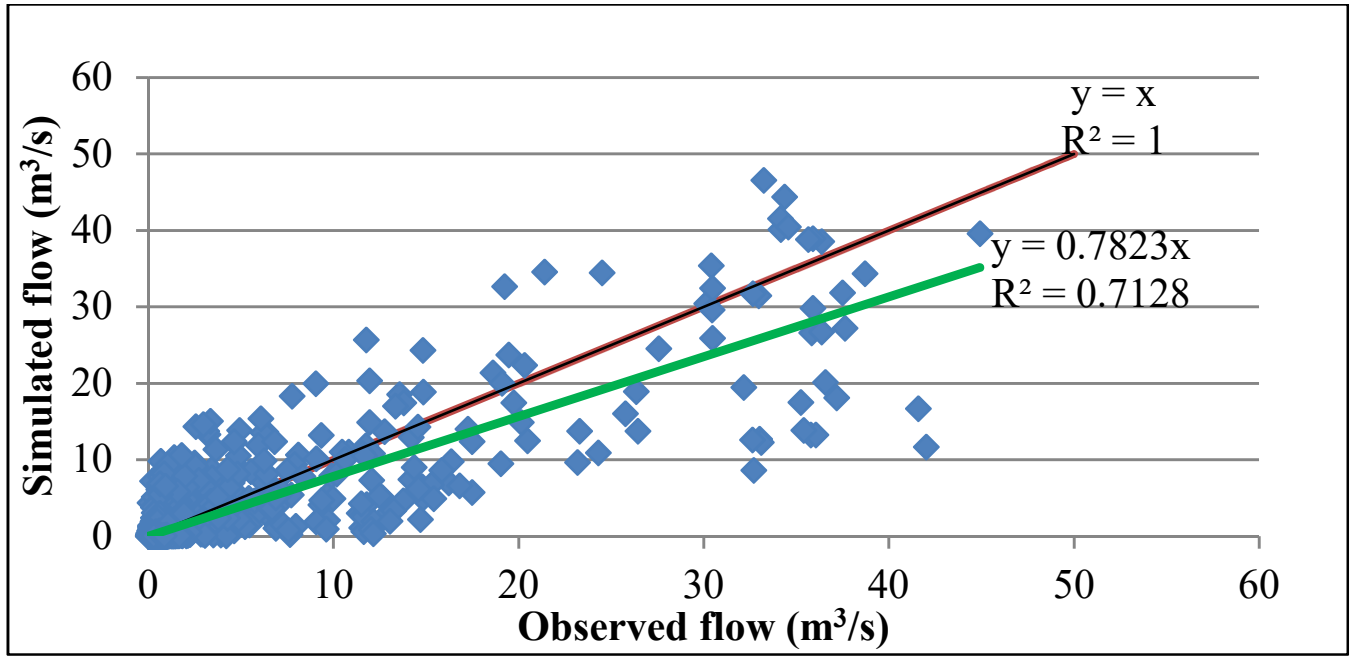

Figure 3.5: Scatter plot during calibration period in the Geba cathment

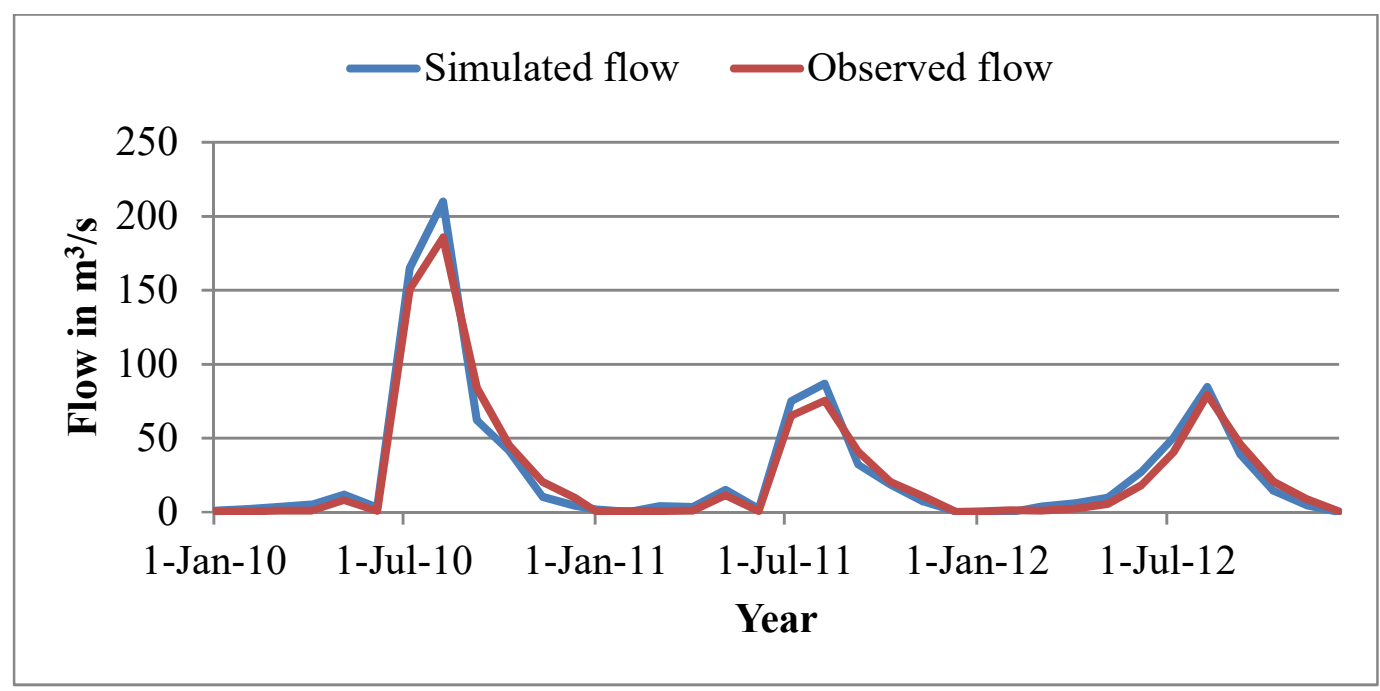

Figure 3.6: Observed and simulated hydrographs during validation period.

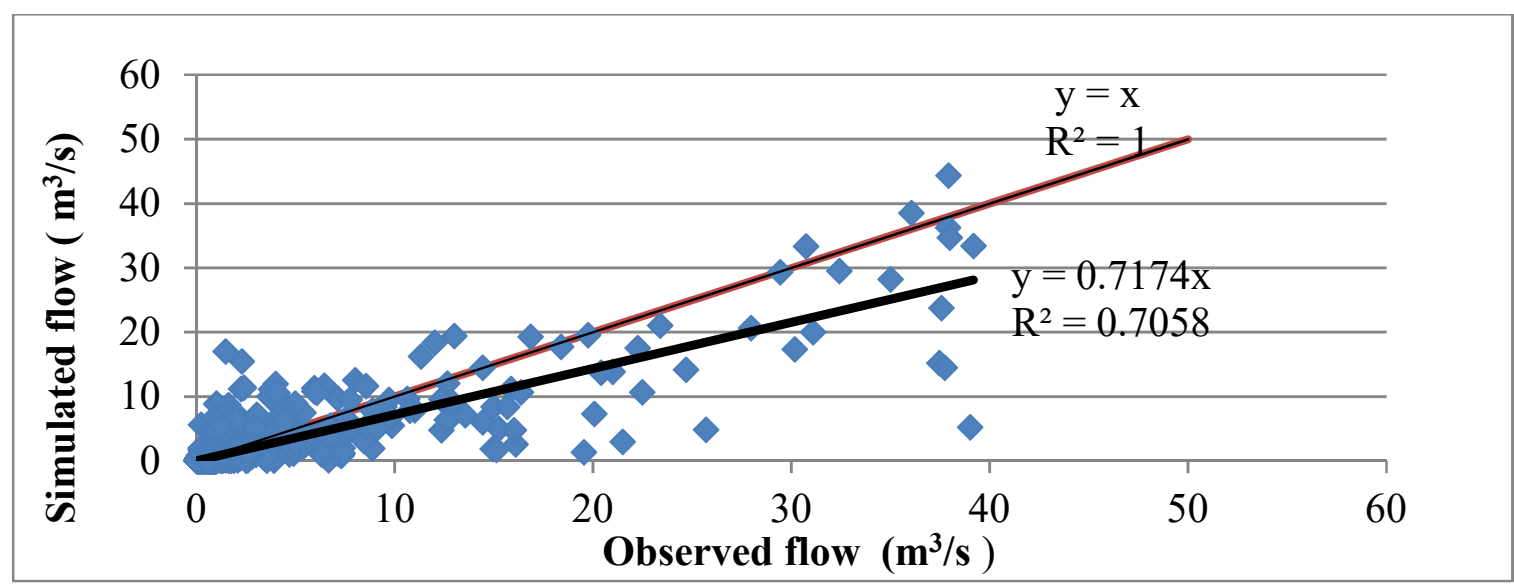

Figure 3.7: Scatter plot during validation period in the Geba cathment 
Table 3.1: Model parameter values for HBV light

\begin{tabular}{|l|l|l|c|}
\hline Parameter & unit & Valid range & $\begin{array}{l}\text { Optimized parameter value } \\
\text { for calibration }\end{array}$ \\
\hline FC & $\mathrm{mm}$ & $(0$, inf $)$ & 850 \\
\hline LP & & {$[0,1]$} & 0.8 \\
\hline BETA & & $(0$, inf $)$ & 0.85 \\
\hline PERC & $\mathrm{mm} / \Delta \mathrm{t}$ & {$[0$, inf $)$} & 60 \\
\hline UZL & $\mathrm{mm}$ & {$[0$, inf $)$} & 50 \\
\hline K0 & $1 / \Delta \mathrm{t}$ & {$[0,1)$} & 0.85 \\
\hline $\mathrm{K} 1$ & $1 / \Delta \mathrm{t}$ & {$[0,1)$} & 0.55 \\
\hline K2 & $1 / \Delta \mathrm{t}$ & {$[0,1)$} & 0.65 \\
\hline MAXBAS & $\Delta \mathrm{t}$ & {$[1,100]$} & 1 \\
\hline Cet & $1 /{ }^{\circ} \mathrm{C}$ & {$[0,1]$} & 0.01 \\
\hline PCALT & $\% / 100 \mathrm{~m}$ & $(-$ inf,inf $)$ & 24 \\
\hline TCALT & ${ }^{\mathrm{O}} \mathrm{C} / 100 \mathrm{~m}$ & $(-$-inf,inf & 0.9 \\
\hline Pelev $_{\text {elev }}$ & $\mathrm{m}$ & $(-$ inf,inf $)$ & 10.5 \\
\hline & $\mathrm{m}$ & $(-$ inf,inf $)$ & 12.5 \\
\hline
\end{tabular}

\subsubsection{Uncertainity Analysis HBV Light Model}

For this study Monte carlo simulation procedure was used to assess the uncertainity analysis in HBV light model.

$\checkmark \quad 150000$ model parameter run was produced

$\checkmark$ After selecting model run just select objective function Reff $>0.6$

$\checkmark$ Upper and lower bound was adopted

\section{Parameter uncertainity}

In similar way to SWAT model the dotty plot for HBV light model is carried by considering the objective function to the crosponding parameter value
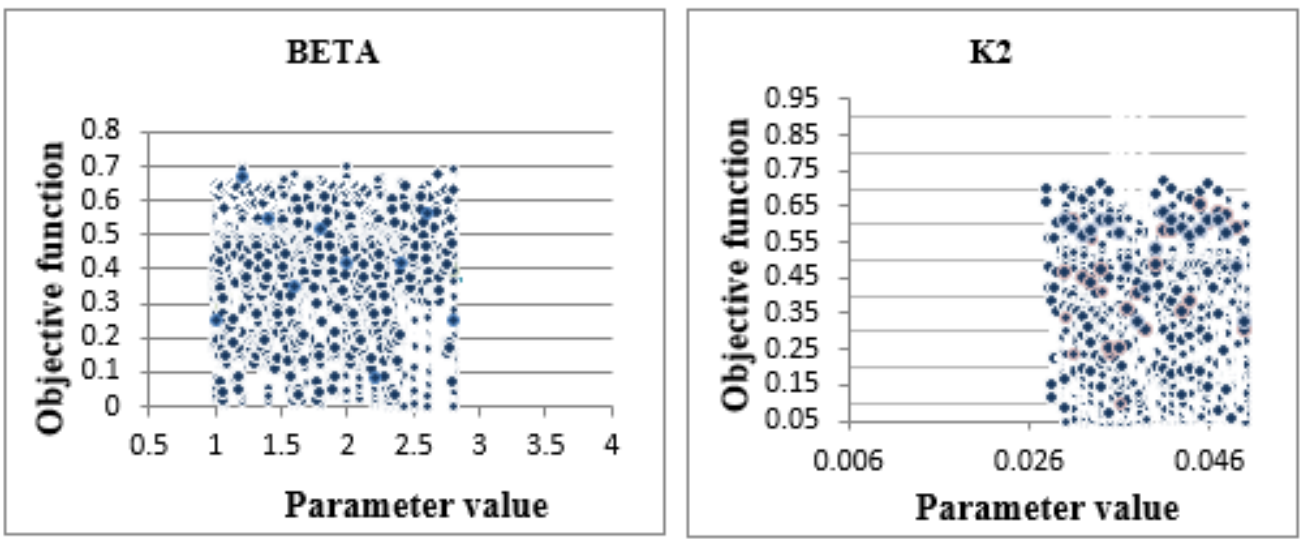

Figure 3.8: Dotty plot for model parameters

These results indicate a large equifinality of parameters and many unconstrained parameters. (Iuliia et.al, 2014) stated the concept of equinfinity concept in different cathment and he got large equinfinity and unconstrainted parameters

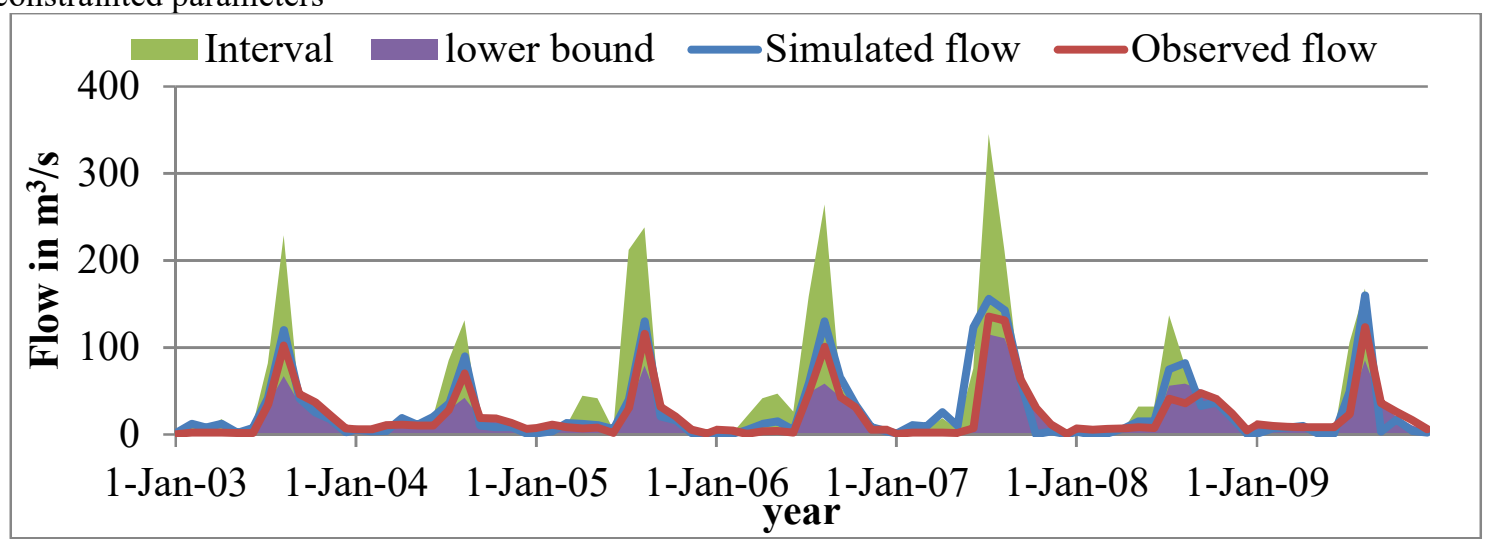

Figure 3.9: Uncertainity analysis in HBV light model

As it is shown in figure 3.8 most part of the simulated hydrograph lays inside the uncertainty range or interval. 
In this study only parameter uncertainty is considered.

Therefore the result of simulated flow is reliable. and researcher found that the simulation result lays outside the unceranity range as (Kumela,2011) stated clearly for uncertainty analysis in muger cathment abay basin,Ethiopia.

\subsection{SWAT Model Development}

\subsubsection{Sensitivity Analysis}

Land use and antecedent soil water conditions (CN2) was the most sensitive of all followed by the ground water determinant parameters for flow in the watershed (GWQMN) and The soil properties of the watershed (SOL_AWC).

The other ground water parameters which flow was sensitive were delay time for aquifer recharge (GW_DELAY) and soil layer depth from soil surface to bottom of the layer (SOL_Z) and the rest parameters are insensitive to runoff simulation

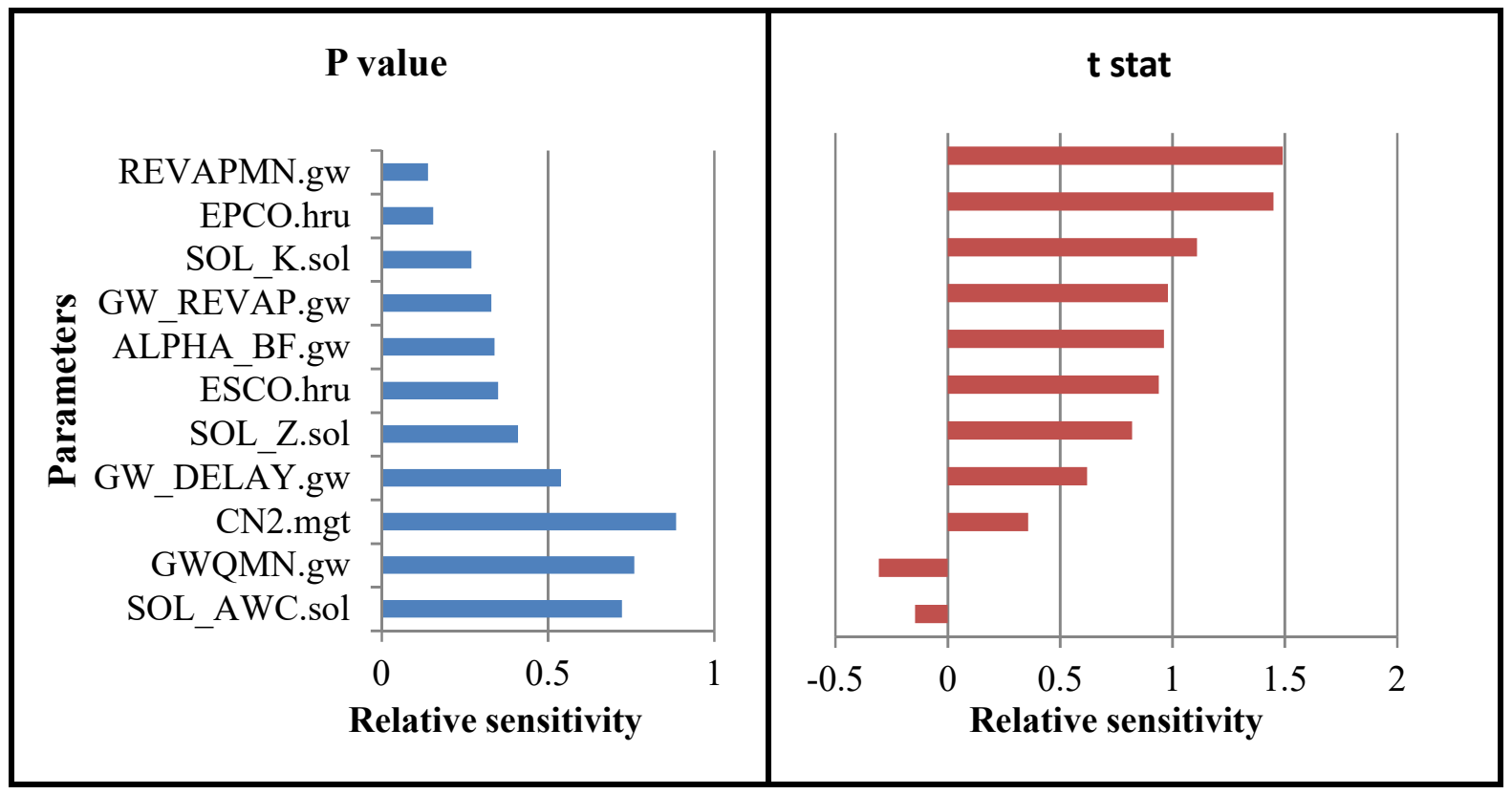

Figure 3.10: Model parameter sensitivity ranking

Since land use and antecedent soil water conditions (CN2) was the most sensitive of the model parameters the identification of parameter should be surface dominance in case of SWAT model.

Note: the t Stat provides a measure of sensitivity (larger absolute values are more sensitive); the $p$ value determines the significance of the sensitivity (a value close to zero has more significance); "R_" and "V_" means relative change and a replacement to the initial parameter values, respectively; and RS- Relative sensitivity values of model parameters have a value Small to Negligible when $0 \leq \mathrm{RS}<0.05$, Medium: $0.05 \leq \mathrm{RS}<0.2$, High: $0.02 \leq \mathrm{RS}<$ 1.0 Very High: $\mathrm{RS} \geq 1.0$.

\subsubsection{Calibration and Validation}

Eight years (from January 1, 2002 to December 31, 2009) which includes one years of warm up, (from January 1, 2002 to December 31, 2003) during calibration. For the validation time period from January 1, 2010 to December 31,2012 , the statistical values in monthly time base of $\mathrm{R}^{2}$, NSE, RSR and PBIAS are $0.81,0.73,0.52,-11 \%$ and $0.72,0.72,0.53,-11 \%$ for calibration and validation respectively The model was calibrated automatically by changing the parameters itself iteratively 1500 times. After adjustmement the result of the model test shows that the $\mathrm{R}^{2}$, NSE, RSR and PBIAS of $89.60 \%, 86.36 \%, 36.76$ and $-8.16 \%$ respectively. Therefore the objective functions were satisfied. 
Table 3.2: Recommended and finally fitted parameter values of flow calibration

\begin{tabular}{|l|l|l|l|}
\hline Parameters & Effect of parameter when its value increase & $\begin{array}{l}\text { Recommended } \\
\text { range }\end{array}$ & $\begin{array}{l}\text { Fitted } \\
\text { value }\end{array}$ \\
\hline ALPHA_BF & $\begin{array}{l}\text { Increase the ground water flow response to changes } \\
\text { in recharge }\end{array}$ & $0-1$ & 0.67 \\
\hline CN2 & Increase surface runoff & $35-98$ & 87.29 \\
\hline GWQMN & Decrease base flow & $0-5000$ & 650 \\
\hline ESCO & Decrease evaporation & $0-1$ & 0.55 \\
\hline SOL_AWC & Increase ground water recharge & $0-1$ & 0.95 \\
\hline CANMAX & Increase the canopy water trapping and storage & $0-10$ & 445 \\
\hline REVAPMN & $\begin{array}{l}\text { Decrease the actual amount of water moving in to } \\
\text { the soil zone in response to water deficiencies }\end{array}$ & $0-500$ & 0.05 \\
\hline GWREVAP & $\begin{array}{l}\text { Decrease base flow by increasing water transfer } \\
\text { from shallow aquifer to root zone }\end{array}$ & $0.02-0.2$ & 1715 \\
\hline SOL_Z & Depth from soil surface to bottom of layer & $0-3500$ & 1500 \\
\hline SOL_K & Saturated hydraulic conductivity & $0-2000$ & 265 \\
\hline GW_DELAY & Ground water delay time & $0-500$ & \\
\hline
\end{tabular}

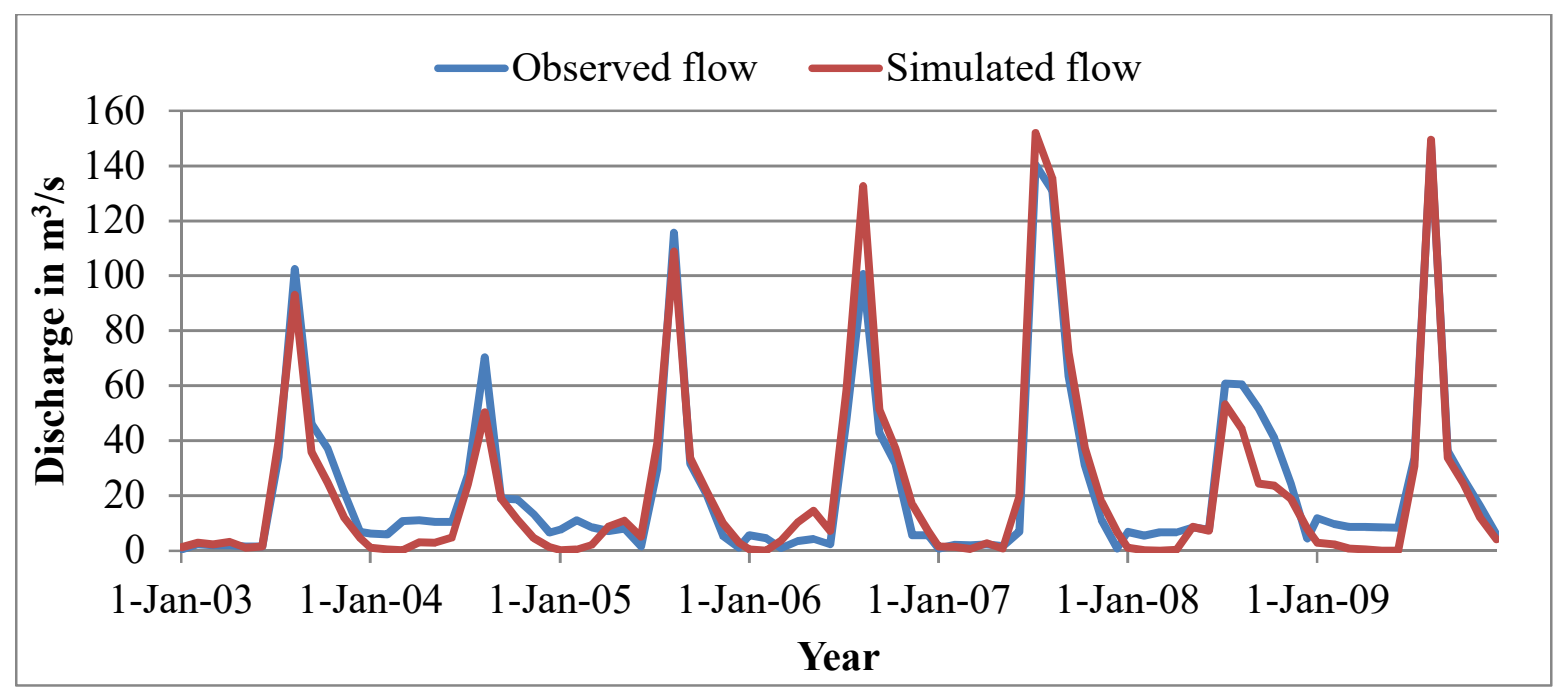

Figure 3.11: Observed and simulated flow hydrographs during calibration period

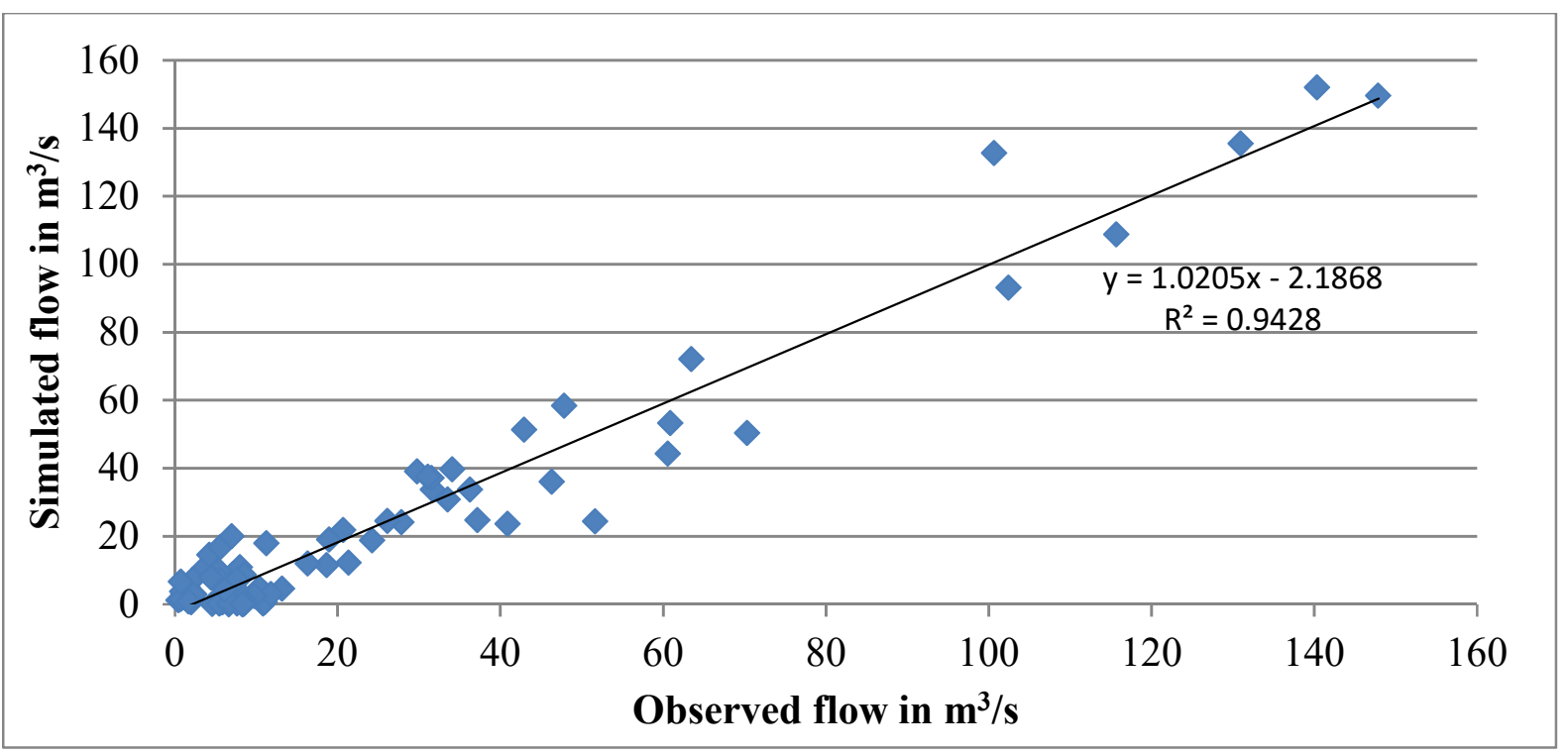

Figure 3.12: Scatter plot during calibration period in the Geba cathment 


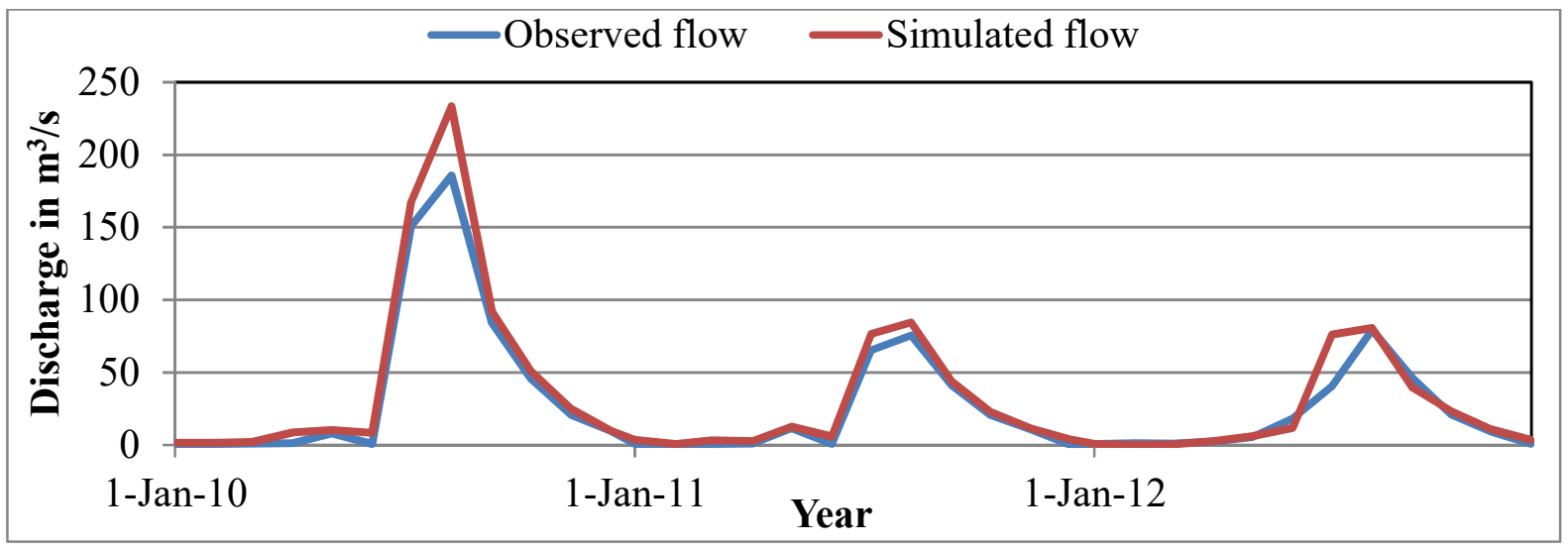

Figure 3.13: Observed and simulated flow hydrographs during validation period

\section{Parameter uncertainity}

The figure 4.15 are plot of parameter values versus objective function. the purpose of this graph is to show the distribution of sample points as well as to give an idea of parameter sensitivity for the selected more sensitive parameters through the calibration and from thegraph it shows that the sample point are scattered around the objective function and it results for its best identifiability of parameters which range around the objective function

9:R_SOL_K(..).sol

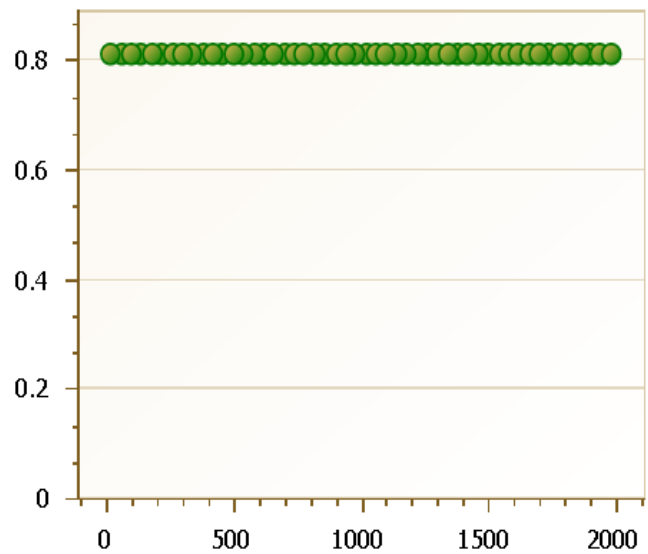

10:R_SOL_AWC(..).sol



Figure 3.14: Sample dotty plot for selective sensitive parameters

N.B: The $\mathrm{x}$ axis indicates parameter range and the $\mathrm{y}$ axis for objective function

As we see from the distribution of the sample point most of the point is aligned away from the objective function which indicates that the HBV light model is less reliable in identifiability of parameter in a comparative approach to that of SWAT model.And the rest parameter set is already mentioned in appendix E.

\subsubsection{Uncertainity Analysis}

The uncertainty of the calibrated model in SUFI-2, 95PPUs, The uncertainty was represented by the p-factor and the $r$-factor. In terms of monthly stream flow, the p-factor and the r-factor was $69 \%$ and 0.64 for calibration. This indicated about $69 \%$ (Out of a perfect $100 \%$ ) of the measured monthly stream flow could be bracketed by the 95PPU with a very narrow 95PPU band of 0.64 (close to a perfect 0 ) in the calibration period.(Wagner et.al,2013). 


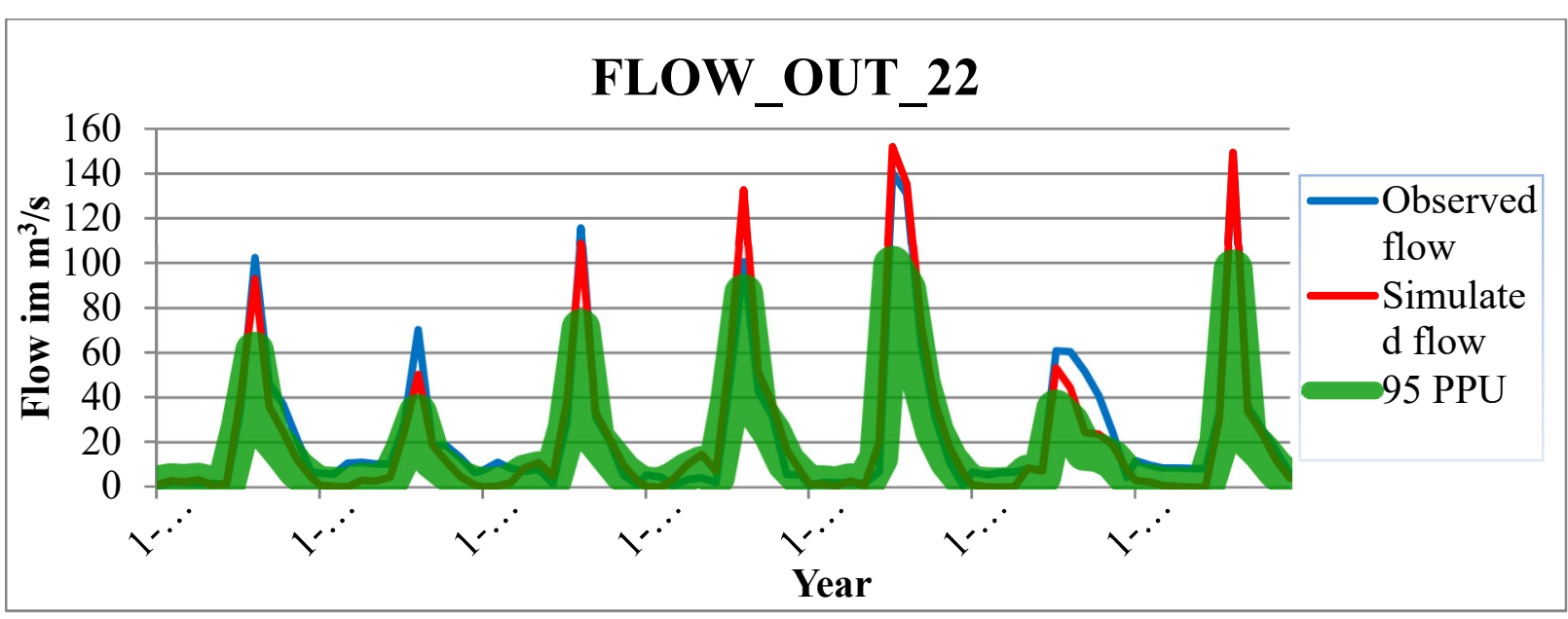

Figure 3.15: Uncertainity plot for SWAT model

Table 3.3: Performance of flow in calibration and validation period

\begin{tabular}{|l|l|l|l|l|l|l|}
\hline Simulation of Runoff & $R_{\text {eff }}$ & ENS & PBIAS & RSR & $\begin{array}{l}\text { Flow weighted } \\
\text { efficiency }\end{array}$ & $\begin{array}{l}\text { Model } \\
\text { efficency/LogReff }\end{array}$ \\
\hline Calibration for HBV light & 0.71 & 0.70 & - & - & 0.79 & $0.71 / 0.74$ \\
\hline Validation for HBV light & 0.71 & 0.71 & - & - & 0.79 & $0.704 / 0.72$ \\
\hline Calibration for SWAT model & 0.81 & 0.73 & -11 & 0.53 & - & - \\
\hline
\end{tabular}

\section{CONCLUSIONS}

The following conclusions can be drawn from the foregoing discussions:The result from sensitivity analysis of the SWAT model showed that the land use and antecedent soil water conditions (CN2) was the most sensitive of all followed by the ground water determinant parameters for flow in the watershed (GWQMN) and The soil properties of the watershed (SOL_AWC).

The parameter which is insensitive or less sensitive are the soil properties of the watershed (EPCO) and the ground water determinant parameters for flow in the watershed (REVAPMN) and the rest parameters are moderately sensitive through out the simulation Thus, for further accuracy of the model a detailed study of land use and antecedent soil water conditions, ground water and soil properties of the watershed are essential for better analysis

The model performance test depicts that SWAT model simulated the discharge better at cathment outlet with highest objective functions.

The majority of the ground surface of the study area covered with closely grown Agricultural land which its existence varying from season to season and with sparse vegetation.

Most of the soil types available in the study area have clay soil texture which is known with its less permeability. These factors generate high runoff from the rainfall events, because unprotected land and less permeable soils are fast to get saturation level(Descheemaker et al., 2006; Abraha, 2009; Tulu, 2010).Consequently, the generation of high runoff depth results for high sediment generation and transport.

The soil routine parameter $\beta$ (shape coefficient), The recession curve, K2 and length of triangular weighted function ( MAXBAS) were found to be the most sensitive parameters only in HBV light and due to this a major portion of the rainfall received Geba catchment quickly as direct runoff ( surface dominance), while most of the rainfall falling in the SWAT model is rather stored and released afterwards by evapotranspiration and base flow ( ground water dominance). This phenomenon has also been incorporated by a water balance analysis, i.e., higher actual evaporation and lower total discharge were estimated SWAT model. This suggests different dominant runoff generation processes in the Geba cathment by the application of both models.

Generally SWAT model is best in simulating the discharge at cathment out let with highest objective function in terms of stastical analysis as compared to HBV Light even most of the the simulated hydrograph lays outside the band. HBV light is good due to uncertainity analysis and parameters are identifiable and the dotty plot have less equinfinity or unconstrainied sample point as compared to SWAT model. Form these regard futher water resource development and analysis selection of HBV light model is best due to best simulation of runoff for the cathment and for the future study of runoff simulation for the cathment proper data collection and analysis should be carried to minimize the uncertainity arises from different source. And from the dynamics of hydrographs both models have less performance in predicting low flow and extreme flood. More over, HBV light over estimate the low flow and the peak flow beside SWAT model under predict the low flow and over predict the peak flow which 
can be attributed to inadequate representation of the spatial variability of rainfall and poor model responses to high rainfall amount.

\section{REFERENCES}

Abbaspour. (2009). SWAT-CUP2: SWAT Calibration and Uncertainty Programs. In A User Manual. Department of System Analysis, Integrated Assessment and Modeling (SIAM), Eawag, Swiss Federal Institute of Aquatic Science and Technology (p. 95). Duebendorf, Switzerland.

Abraha. (2009). Assessment of spatial and temporal variability of river discharge, sediment yield and sedimentfixed nutrient export in Geba River catchment, northern Ethiopia. PhD thesis, Katholieke Universiteit Leuven, Belgium. .

Birhane et al. (2013). Estimation of monthly flow for ungauged catchment (Case Study Baro - Akobo basin) Ethiopia. MSc thesis. Addis Ababa University, Ethiopia.

Finicia et al. (2008). Understanding catchment behavior through stepwise model concept improvement, Water Resour. Res., 44, W01402, doi: 10.1029/2006WR005563.

Gebre yohannes et al. (2010). Large-scale geological mapping of the Geba basin, northern Ethiopia [Tigray Livelihood Papers; 9].

Gonfa. (1996). Climate classification of Ethiopia. Addis Ababa, Ethiopia. .

Hundecha. ( 2005). regionalization Parameters of Conceptual Rainfall - Runoff Model, . University of Stuttgart Germany.

IHMS. (2006). "Integrated Hydrological Modeling System Manual." Version 5.1.

Iuliia et.al. (2014). Simulating Water Resource Availability under Data Scarcity—A Case Study for the Ferghana Valley (Central Asia). 6, 3270-3299.

Kumela. (2011). performance comparsion of rainfall runoff model on Muger cathment ,abay basin, M.Sc. Thesis, addis ababa,ehiopia.

Moreda. (1999). Conceptual Rainfall-Runoff Models for Different Time Steps with Special Consideration for Semi-arid and Arid Catchments Laboratory of Hydrology and Inter-University Program in Water Resources Engineering.

Wagener et al. (2003). towards reduced uncertainty in conceptual rainfall-runoff modeling: dynamic identifiability analysis, Hydrol. Processes. pp. 17(2), 455-476. 